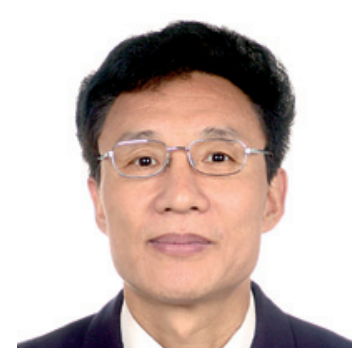

\title{
China's chemists should avoid the Vanity Fair
}

\author{
Problems in Chinese science are well documented. The slow pace of reform \\ affects chemists more than most, says Nai-Xing Wang.
}

$\mathrm{C}$ hange comes slowly in China and necessary change to the way Chinese science works is coming very slowly indeed. Despite suggestions earlier this year that reform was in the air, Chinese administrators still stick to their system of allotting funding according to the impact factors of the journals in which we publish our research. And chemistry is the field most adversely affected by this.

I have worked as a researcher in organic chemistry for many years, and am greatly concerned about the way Chinese chemistry is heading. Chemistry has made a great contribution to human society, but right now it seems that chemistry research in China has turned into a Vanity Fair.

The biggest problem remains the obsession with journal impact factors. Generally speaking, articles in journals with high impact factors are judged to appeal most to readers, but not every paper published in a high-impactfactor journal is high quality, and papers published in lower-ranked journals are never worthless. Yet some administrators in China take a very crude approach: high-impact-factor publications mean excellent work.

Research proposals are judged according to the impact factor of a scientist's previous publications. (And referees are usually selected on these criteria too.) Worse, the salaries of my chemistry colleagues go up or down depending on a complex mathematical formula based on the impact factor of the journals in which we publish our work - which we must supply in a detailed list.

An impact factor is a measure only of the frequency with which the average article in a journal is cited in a given period of time. So it is no surprise to find journals judged to have high impact in fashionable research areas, such as nanotechnology. For example, the impact factor of Nanotechnology Letters was 9.99 in 2010, but we should not judge this journal twice as valuable as the Journal of Organic Chemistry, with an impact factor of $4.21 \mathrm{in} 2010$. And some researchers in nanotechnology have not used mainstream techniques such as nuclear magnetic resonance, mass spectrography, infrared or ultraviolet spectroscopy, or X-ray diffraction. They sometimes get by with just one instrument: an electron microscope. Some research on 'novel' materials is nothing more than pictures taken with such a microscope. In contrast, papers in organic synthetic chemistry often feature new synthetic routes and skills, but because some of the reactions involved are common, they are too often dismissed as lacking innovation and novelty.

If a high impact factor is the only goal of chemistry research, then chemistry is no longer science. It is changed to a field of fame and game. There are other effects too. Administrators in almost every university and research institute

\section{DNATURE.COM}

Discuss this article online at:

go.nature.com/05rmeh

like to evaluate researchers by their papers at the end of each year. As a result, chemists often choose easy research topics that can be written up inside a year. There are still some chemistry projects that last five years, but they are rare. Some topics are finished and written up inside six months. It is not unusual for a professor to publish ten papers in a year. And the outcome of a single project is usually split into several parts to produce more papers, which individually offer less information to readers.

I realize that such pressures are common in academia everywhere, but they are most serious in China now, because of the rigid reliance on impact factors, and they are worst in chemistry, because, in chemistry, it is much easier to produce a scientific paper from limited work. Often, papers do not describe truly new chemical reactions, just variations on an established theme. Someone publishes a new reaction, and some chemists just introduce a 'novel' substituent group and run the experiment under 'novel' conditions. The predecessors open a new door and some chemists follow them through wearing different 'novel' clothing.

One way to improve the situation, without slipping back to the days when research funding was allocated to favourites and friends, would be to judge scientists in China not just on journal impact factors but on the citations their papers receive after, say, two years, to see whether their work stands the test of time.

It is right to push Chinese scientists to publish in international journals, but currently there is too much emphasis on presentation and fancy concepts, and too little on solid, high-quality work. Texts that teach scientists how to write world-class papers with a good structure including among other things, an abstract and an introduction - are popular in China at the moment. But too often these perfectly packaged and neatly written papers discuss empty concepts.

Additional pressure on chemistry in China comes from an increasing emphasis on making research projects 'useful.' China has a big population and lacks resources, so it is right to emphasize the importance of applied chemistry research, which needs an element of process engineering. But science is not directly equal to productivity. Pure chemistry, which explores the unknown and provides new tools for scientists, must not be overlooked.

We are now more than halfway through 2011, the Year of Chemistry. If China is to truly celebrate the discipline and produce good chemistry rather than lots of papers, then change needs to come quickly.

Nai-Xing Wang is a professor in the Technical Institute of Physics and Chemistry, Chinese Academy of Sciences, Beijing.

e-mail:nxwang@mail.ipc.ac.cn 